\title{
Development of Antioxidants Synthesized by Phase Transfer Catalysts for Lubricating Oil
}

\author{
Noura El Mehbad \\ Faculty of Science, Najran University, Najran, Kingdom of Saudi Arabia. \\ Email: dr.n.almehbad@hotmail.com \\ Received September $26^{\text {th }}$, 2013; revised October $23^{\text {rd }}$, 2013; accepted December $20^{\text {th }}$, 2013 \\ Copyright (C) 2014 Noura El Mehbad. This is an open access article distributed under the Creative Commons Attribution License, \\ which permits unrestricted use, distribution, and reproduction in any medium, provided the original work is properly cited. In accor- \\ dance of the Creative Commons Attribution License all Copyrights (C) 2014 are reserved for SCIRP and the owner of the intellectual \\ property Noura El Mehbad. All Copyright (C) 2014 are guarded by law and by SCIRP as a guardian.
}

\section{ABSTRACT}

The oxidation stability of lubricating oil has a critical influence on the oil performance during service. In this paper, dibenzyl-S-phenyl thioglyconitrile and other derivatives were prepared by phase transfer catalysts and investigated as antioxidants. These compounds were added to oil in different concentrations. The antioxidants activities of different dosages were evaluated and the mechanism was suggested according to micelle and its thermodynamics. The oxidation of the oil has been carried out at different time intervals. The degradation of the oil has been monitored by total acid formation. Oxidation stability of lube oil was largely affected by sulphur and concentration of aromatic hydrocarbons in oil, with the increased sulphur content increasing oxidation stability. The prepared compounds gave higher oxidation stability than imported compound (IRCANOX L 135CIBA).

\section{KEYWORDS}

Phase Transfer Catalysts; Lube Oil; Antioxidants

\section{Introduction}

One of imported properties of lubricating base oil is their oxidation stability. It is well known that oxidation stability of base oil is very sensitive to their composition, especially to sulphur and aromatic hydrocarbon content. To reach a maximum oxidation stability of lubricating oil, the concept of optimum aromaticity was introduced by Van Fuchs and Dimond in 1942 [1], and it was recently confirmed even for antioxidant containing oils [2]. Antioxidants can generally be considered as free radical inhibitors of peroxides decomposers, and may vary in chemical structures. Three types of additives are proved to be the success fuel in controlling the degradation of lubricating oils, radical scavengers, and hypoperoxide decomposers, as well as synergistic mixtures of both of them. The polyfunction alized phenols linked to hetero cyclic derivatives had been evaluated as antioxidants [3].

Organic sulphur compounds are used in lubricating compositions for their extreme pressure and anti wear as well as their oxidation stability [4].
The aim of this paper is to study the effect of phase transfer catalysts on the yield of dibenzyl-S-phenyl 1 thio glycol nitrile and its derivative used as antioxidant. A comparison between the synthesized compounds and the imported (IRCANOX L 135-CIBA) was obtained.

\section{Experimental}

The paraffinic gas oil has physic chemical properties were listed in Table 1.

Preparation antioxidants dibenzyl-S-phenyl thio glyconitrile (A):

$$
\begin{aligned}
& \mathrm{C}_{6} \mathrm{H}_{5} \mathrm{SCH}_{2} \mathrm{CN}+2 \mathrm{C}_{6} \mathrm{H}_{5} \mathrm{CH}_{2} \mathrm{Cl}+\mathrm{NaOH} \stackrel{\text { PTC }}{\longrightarrow} \\
& \mathrm{C}_{6} \mathrm{H}_{5} \mathrm{SC}\left(\mathrm{CH}_{2} \mathrm{C}_{6} \mathrm{H}_{5}\right)\left(\mathrm{CH}_{2} \mathrm{C}_{6} \mathrm{H}_{5}\right) \mathrm{CN}
\end{aligned}
$$

S-Phenyl thio glyconitrile (7.5 gm $0.05 \mathrm{~mol}$ ), benzyl chloride 14.4 g $0.011 \mathrm{~mol}, 50 \%$ aqueous $\mathrm{NaOH} 20 \mathrm{~mol}$, phase transfer catalyst (benzyl triethanol ammonium chloride prepared by Omar et al. [4], 0.25 gm were stirred vigorously under nitrogen, the mixture was stirred for three hours. Then diluted with water, prtoduct dibenzyl 
Table 1. Characteristics of the gas oil.

\begin{tabular}{ccc}
\hline Property & Test method & Gas oil \\
\hline Specific gravity 60/60F & IP 160/87 & 0.88 \\
Pour point C & IP 15/67 (86) & 17 \\
Cloud point C & IP 219182 & 26 \\
Viscoosity at 40 C cST & ASTM D 445 & 28.7 \\
Total sulphur wt\% & IP 266/87 & 0.39 \\
n-paraffin wt\% & ASTM 3238/85 & 65.5 \\
Naphthenes wt\% & ASTM 3238/85 & 23.5 \\
Aromatic wt\% & ASTM 3238/85 & 10.8 \\
Carbon residue wt\% & ASTM D 524 & 1.6 \\
Sulphur content wt\% & ASTM D 4294 & 1.5 \\
Ash content wt\% & ASTM D 482 & 0.03 \\
\hline
\end{tabular}

-S-phenyl thio glyconitrile, filtererd and cristalized from methanol, mp. 152 C, with yield $85 \%$ and purity $98 \%$ [5].

Preparation antioxidants dibenzyl phenyl glyconitrile with yield $90 \%$ and purity $97 \%$ (B):

$$
\begin{aligned}
& \mathrm{C}_{6} \mathrm{H}_{5} \mathrm{CH}_{2} \mathrm{CN}+2 \mathrm{C}_{6} \mathrm{H}_{5} \mathrm{CH}_{2} \mathrm{Cl}+\mathrm{NaOH} \stackrel{\text { PTC }}{\longrightarrow} \\
& \mathrm{C}_{6} \mathrm{H}_{5} \mathrm{C}\left(\mathrm{CH}_{2} \mathrm{C}_{6} \mathrm{H}_{5}\right)_{2} \mathrm{CN}
\end{aligned}
$$

Oxidation test was carried out at $120 \mathrm{C}$ according to ASTM D 943 standard method. The dose of antioxidants was added in different concentrations ranging from $10^{-5}$ to $0.1 \mathrm{~mole} / \mathrm{L}$. The oil samples after $12,24,48$ and 72 hours of oxidation time were analyzed for total acid number.

Surface and interfacial tension measurement:

Surface tension of different concentration for $10^{-5}$ to $0.1 \mathrm{~mole} / \mathrm{L}$ of the synthesized antioxidants was measured by using a tensiometer Kruss model 8451 in petroleum ether at $30 \mathrm{nC}$ according to Omar et al. [4].

\section{Results and Discussions}

The yields of alkylation product in the presence benzyl triethyl ammonium chloride as the catalyst are listed in the following:

\begin{tabular}{cc}
\hline Additive & Percentage of yield \% \\
\hline A & 82 \\
B & 87 \\
\hline
\end{tabular}

The yield was found to be much higher using benzyl chloride in alkylation and faster. These results suggest that the product distribution is thermodynamically with highly reactive benzyl chloride but kinetically controlled in reaction with less reactive compound. It found that, the yield with benzyl chloride increased with increasing amounts of $\mathrm{NaOH}$ up to 2 moles per mole of phenyl acetonitrile, beyond which no further increase was observed. Also increasing the concentration of the catalyst benzyl triethyl ammonium chloride lead to increase the yield of product until the critical concentration 0.025 mole per mole of phenyl acetonitrile as shown in the following Table 2.

To suggest the mechanism of additive as antioxidant and improving the oxidation stability of oil sample, it must be studied the physical properties of oil and additives in oil phase. Values of the surface tensions at $25 \mathrm{C}$ obtained for various concentrations of additives A and B in petroleum ether are shown graphically in Figure 1.

From the intersection point in the vs log c curves, the critical micelle concentration (CMC) is determined. The surface properties are calculated according to Omar (2001) [4].

It found the CMC value decrease and depends on additive molecular weight. This indicating the structure of alkyl group is a controlling factor in micellization processes (Figure 1). The effectiveness $\left(\pi_{\mathrm{cmc}}\right)$ is maximum surface excess and minimum surface area for additives under study was calculated according to Omar et al. [4]. Studying the results in Table 3 shows that the synthesisized additive $B$ has large value of effectiveness and minimum surface area $A_{\min }$, this mean that the additive is the most efficient one that favors adsorption in the micelliza-

Table 2. Effect of concentration of phase transfer catalyst on the yield of product at concentration $2 \mathrm{~mole} / \mathrm{mol} / \mathrm{reac}-$ tant.

\begin{tabular}{ccc}
\hline $\begin{array}{c}\text { Concentration of PHC } \\
\text { Mole/mole of reactant }\end{array}$ & Yield \% \\
\hline PHC & A & B \\
0.015 & 72 & 80 \\
0.02 & 82 & 91 \\
0.025 & 81 & 87 \\
\hline
\end{tabular}

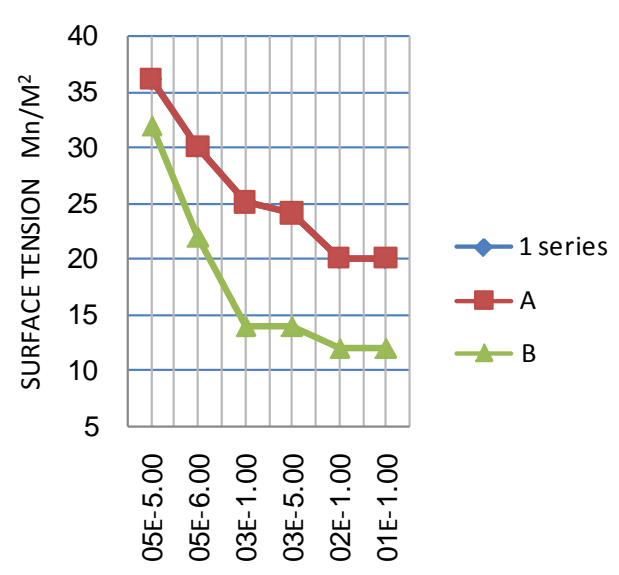

Figure 1. Effect of different concentrations of additives on surface tension. 
Table 3. Surface and thermodynamic of synthesized additives.

\begin{tabular}{cccccccc}
\hline Additive & $\mathrm{CMc}$ & $\pi_{\mathrm{cmc}\left(\mathrm{mn} / \mathrm{m}^{2}\right)}$ & $\pi_{\max } \times 10^{-4} \mathrm{~mol} / \mathrm{ml}$ & $\mathbf{A}_{\min }$ & $\Delta \mathrm{G}_{\operatorname{mic}} \mathrm{KJ} / \mathrm{mol}$ & $\Delta \mathrm{G}_{\text {ads }} \mathrm{KJ} / \mathrm{mol}$ & $\pi_{\max } \times 10^{-4} \mathrm{~mol} / \mathrm{ml}$ \\
\hline A & $5 \times 10^{-3}$ & 12 & 1.21 & 0.18 & -13.2 & -19.2 & 1.21 \\
B & $1 \times 10^{-3}$ & 17 & 1.5 & 0.25 & -18.11 & -23.6 & 1.5 \\
\hline
\end{tabular}

tion processes and gives a greater lowering in the surface tension. As the result the change in the hydrophobic moites for the additives under study affect their micellization. Further more evident the standard free energies of micellization $\Delta \mathrm{G}_{\text {mic }}$ and adsorption $\Delta \mathrm{G}_{\text {ads }}$ prove additive $\mathrm{B}$ has ability to micellization faster than $\mathrm{B}$ and tend to form most stable micelle. i.e the molecule of additive $B$ favour micellization rather than adsorption at interface. The minimum area per molecule also increases with moiety of hydrophobic portion of molecule. This value reflects the transfer of methylene group from oil environment to the interior of the micelle, i.e introduction of additional methylene groups induced micellization and its stability. The physic-chemical properties of oil are reported in Table 1 . The amount of aromatic hydrocarbons was about $10 \%$, while amount of polar hetero compounds was almost negligible and has low carbon residue content. As we known the oxidation tests of oil was studied by oxidizing the oil at $120 \mathrm{C}$ and evaluation oxidation stability by determination of the viscosity at $100 \mathrm{C}$ and total acid number after different times. The results given in Table 4 show that both viscosity and total acid number increase with the increasing time of oxidation under the same conditions. We suggest due to free radical and formation of sludge and acidic compounds. The synthesized additive B was compare with additive A as antioxidant. In addition, kinematic viscosity at $100 \mathrm{C}$, acid number used as complementary evaluation parameters. Amount of oxidation product formed by oxidation was determined by fractionation of oil before and after oxidation tests.

Changes in viscosity characteristics of oil after oxidation are shows in Table 5 . There were great differences between two additives $\mathrm{A}$ and $\mathrm{B}$, the oxidation time slightly increase the viscosity, this due to formation of carboxylic acids from oxidation processes. The additives $\mathrm{A}$ and $\mathrm{B}$ retard the increasing of oil viscosity by increasing the oxidation time. On the other hand the oxidation inhibition efficiency of these additives increases with increasing their concentration and reach optimums at the critical concentration of each additive $(\mathrm{cmc})$. Beyond the cmc value, the oxidation stability of the oil not changes and remains stable. There is a good relation between oxidation stability of oil with cmc of each additive. These results are confirmed by determination the total acid number as shown in Table 6 . It shows that, addition of additives to oil also inhibit the increasing of total acid number by oxidation. Also additive $\mathrm{B}$ gives the best re
Table 4. Viscosity and total acid numbers of oil after oxidations tests.

\begin{tabular}{lccc}
\hline Test & $30 \mathrm{~h}$ & $50 \mathrm{~h}$ & $70 \mathrm{~h}$ \\
\hline Viscosity (cSt@ 100 $\left.{ }^{\circ} \mathrm{C}\right)$ & 30 & 32.8 & 34 \\
Total acid number, mg, KOH/g & 2.5 & 3.8 & 5.2 \\
\hline
\end{tabular}

Table 5. Effect of different concentrations of additives on viscosity.

\begin{tabular}{ccccccccccc}
\hline Compound & \multicolumn{10}{c}{ Viscosity } \\
\hline & \multicolumn{1}{c}{$10^{-4} \mathrm{~mol} / \mathrm{L}$} & \multicolumn{3}{c}{$\mathrm{mol} / \mathrm{L}$} & \multicolumn{3}{c}{$5 \times 10^{-3} \mathrm{~mol} / \mathrm{L}$} \\
\cline { 2 - 10 } & $30 \mathrm{~h}$ & $50 \mathrm{~h}$ & $70 \mathrm{~h}$ & $30 \mathrm{~h}$ & $50 \mathrm{~h}$ & $70 \mathrm{~h}$ & $30 \mathrm{~h}$ & $50 \mathrm{~h}$ & $70 \mathrm{~h}$ \\
\hline $\mathrm{B}$ & 28 & 30 & 31 & 29.2 & 31.5 & 33.5 & 29.5 & 31.5 & 33.5 \\
$\mathrm{~A}$ & 27 & 28 & 30 & 28 & 29 & 31.5 & 29 & 31 & 33 \\
\hline
\end{tabular}

Table 6. Effect of different concentrations of additives on total acid number.

\begin{tabular}{cccccc}
\hline \multirow{2}{*}{ Compound } & \multicolumn{5}{c}{ Total acid number } \\
\cline { 2 - 6 } & $30 \mathrm{~h}$ & $40 \mathrm{~h}$ & $50 \mathrm{~h}$ & $60 \mathrm{~h}$ & $70 \mathrm{~h}$ \\
\hline $\mathrm{A}$ & 1.5 & 2 & 2.8 & 3 & 3.2 \\
$\mathrm{~B}$ & 0.6 & 1.5 & 1.4 & 1.3 & 1.2 \\
\hline
\end{tabular}

sults at $10^{-3} \mathrm{~mol} / \mathrm{L}$ with respect to its $\mathrm{cmc}$. The obtain results provide possibility of assuming that the action mechanism of micelle in inhibiting RO. Radical. This means that additive $\mathrm{A}$ and $\mathrm{B}$ act as antioxidant is based on formation of micelle in oil phase. This micelle interacts with polar oxygen-containing product formed during oxidation and abstract or incorporates them in its core. As the results products are removed inside this core and inhibit propagation step of reaction. As the results, decreasing the amount of free radicals intermediates. On the other hand, the additive $\mathrm{B}$ is give micelles at lower concentrations and more stable than additive A according to surface and thermodynamic properties as shown in (Table 3). It can be suggested that novel mechanism for antioxidants according surface properties of additive.

Further work need to study synergistic effect between two additive and micelle structure.

\section{Conclusion}

Oil-soluble antioxidants prepared by phase transfer catalyst give a novel type of inhibition, micelle inhibition. We suggest the free radicals species catching inside micelle core. The surface and thermodynamic parameters 
are proved to be successful in controlling the oxidation stability of oil and depend on cmc of each additive. In the next paper, we will study the synergistic effect between two additives and micelle structure.

\section{REFERENCES}

[1] G. H. Von Fuchs and H. Diamonid, "Oxidation Characteristics of Lubricating Oils,” Industrial \& Engineering Chemistry, Vol. 34, No. 8, 1942, pp. 927-937. http://dx.doi.org/10.1021/ie50392a007

[2] X. Maleville, D. Faure, A. Legros and J. C. Hipeaux, "Oxidation of Mineral Base Oils of Petroleum Origin: The Relationship between Chemical Composition, Thickening, and Composition of Degradation Products,” Lu- brication Science, Vol. 9, No. 1, 1996, pp. 3-60. http://dx.doi.org/10.1002/ls.3010090102

[3] E. S. El Ashry, M. E. El-Rafi, M. H. Elnagdi, H. H. AbouElnaga, W. M. A. Abdelazim and Y. M. Boghdad, “Antioxidant Additives for Lubricating Oils. Synthesis and Evaluation of some Polyfunctionalized Phenols Linked to Heterocycles,” Jordon Journal of Chemistry, Vol. 4, 2009, pp. 223-231.

[4] A. M. A. Omar, "Separation of Emulsifiable Oil from a Flotation Solution by Surface Tension Control," Adsorption Science \& Technology, Vol. 19, No. 1, 2001, pp. 91100. http://dx.doi.org/10.1260/0263617011494006

[5] C. M. Starks and C. Liotta, "Phase Transfer Catalysis," Academic Press, Waltham, 1978, pp. 181-191. 